\title{
Influence of preparation method on hydroxyapatite porous scaffolds
}

\author{
N MONMATURAPOJ* and C YATONGCHAI \\ National Metal and Materials Technology Center, Pathumthani 12120, Thailand
}

MS received 3 June 2009

\begin{abstract}
Hydroxyapatite (HA) is extensively used in medical applications as an artificial bone because of its similarity to the natural components of human bones and for its excellent biocompatibility. The porous structure of HA ceramics is more generally used as a scaffold. Many techniques, which are performed under fluid system, have been applied to fabricate HA porous scaffolds. In this work, polymeric sponge technique was employed in the preparation of HA slurry appropriated for porous ceramic fabrication. Effort for strength improvement was made on porous $\mathrm{HA}$ ceramic in several aspects. The effect of $\mathrm{HA} /$ water, binder/plasticizer ratios and dispersant content on the rheological properties of HA suspension in combination with the addition of $\mathrm{SiC}$ and $\mathrm{SiO}_{2}$ on the compressive strength of porous bodies were investigated and discussed.
\end{abstract}

Keywords. Hydroxyapatite; porous scaffolds; slurry preparation; rheological behaviour.

\section{Introduction}

Biomaterials, for instance, hydroxyapatite, bioglass, polymers and metals, were used as a bone substitution during the past 30 years. Hydroxyapatite $\left(\mathrm{HA}: \mathrm{Ca}_{10}\left(\mathrm{PO}_{4}\right)_{6}\right.$ $\left.(\mathrm{OH})_{2}\right)$ specifically is well known for its resemblance to the major component in the hard tissue of human beings and animals, therefore, it has been widely employed in medical applications mainly for non-load bearing parts (Kweh et al 1999; Ozgur and Tas 1999; Tian and Tian 2001; Ramay and Zhang 2003; Saiz et al 2007; Zhang and Zhu 2007). Recently, the studies of HA have been concentrated on improving its properties particularly the fabrication of a porous form as a porous scaffold for the repair and/or substitution of damaged or lost bone tissue (Kweh et al 1999; Tian and Tian 2001; Ramay and Zhang 2003; Saiz et al 2007; Zhang and Zhu 2007). The porous network or interconnected pores in HA structure allow the tissue to infiltrate, which further enhances the implant tissue attachment (Itoh et al 2006). Several techniques, for example, pore-creating volatile particles, ceramic foaming technique and polymeric sponge technique have been investigated to obtain the required porous scaffolds (Sopyan et al 2007). The polymeric sponge technique, which offers great flexibility, is particularly of interest due to its superior advantages such as possibility to control the pore size, for several desired complex shapes and straightforward process (Tian and Tian 2001).

The polymeric sponge technique involves coating of open-cell polymeric foam with ceramic slurry followed by burning out of polymeric foam through sintering

*Author for correspondence (narupork@mtec.or.th) process which yields a replica of the original polymer foam in the ceramic foam structure. However, the properties of the hydroxyapatite scaffold prepared through the polymeric sponge route highly depend on the slurry properties including homogeneity, rheology and dispersion (Zhang et al 2006). The influence of solid loading and type of dispersant on the rheological behaviour of concentrated hydroxyapatite suspensions was studied and reported (Liu 1998; Gardini and Galassi 2003; Pretto et al 2003; Chen et al 2006; Tian et al 2007).

In this study, the HA slurries were prepared and their rheological behaviours were studied to find an optimized stable slurry. The factors such as HA/water ratio, binder/ plasticizer ratio and dispersant content, which influence on HA suspension were investigated. Then, the optimized slurry with the addition of $\mathrm{SiC}$ and $\mathrm{SiO}_{2}$ for mechanical strength improvement was used to produce the macroporous hydroxyapatites in polymeric sponge method for physical and mechanical properties characterization.

\section{Experimental}

\subsection{Materials}

The starting materials $\mathrm{CaHPO}_{4}$ and $\mathrm{CaCO}_{3}$ with molar ratio of 1.5 as seen in (1) were used to produce pure HA stoichiometric powder via solid-state method.

$$
\begin{aligned}
4 \mathrm{CaCO}_{3}+6 \mathrm{CaHPO}_{4} \rightarrow & \mathrm{Ca}_{10}\left(\mathrm{PO}_{4}\right)_{6}(\mathrm{OH})_{2}+ \\
& 2 \mathrm{H}_{2} \mathrm{O}+4 \mathrm{CO}_{2} .
\end{aligned}
$$

$\mathrm{CaCO}_{3}$ (Fluka, Germany) and $\mathrm{CaHPO}_{4}$ (Sigma-Aldrich, Germany) were milled using zirconia balls in deionized 
(DI) water medium for $48 \mathrm{~h}$ and then dried in an oven at $80^{\circ} \mathrm{C}$ for $24 \mathrm{~h}$ prior to the preparation of HA powder. The calcination step was achieved by heating HA powder at $900^{\circ} \mathrm{C}$ for $1 \mathrm{~h}$ at the heating rate of $5^{\circ} \mathrm{C} / \mathrm{min}$ to modify the properties of HA powder suitable for the slurry preparation.

\subsection{Preparation of slurry and scaffolds}

The porous scaffolds were prepared by using polyurethane (PU) foams infiltrated with hydroxyapatite slurry. The self-synthesized HA powder, polyvinyl alcohol (PVA: Fluka, Germany) as a binder, polyethylene glycol (PEG: Fluka, Germany) as a plasticizer, dispersant (Dispex A40: Ciba, Australia) and DI water were mixed together in a ball mill for $24 \mathrm{~h}$ to formulate the ceramic slurry. Dispex A40 was chosen as a dispersant in this study due to its high negative zeta potential values which induce the most capable electrostatic stabilizers and will facilitate to attain high solids loading (Rodriguez-Lorenzo et al 2001). Meanwhile, the long milling time of $24 \mathrm{~h}$ is essential in order to eliminate the agglomerated particles and to obtain bimodal size distribution which can produce closer packing during densification process since the smaller particles can fit into interstices among bigger particles (Sadeghian et al 2006). To investigate the effect of slurry rheological behaviours on physical and mechanical properties of porous ceramics, the HA/water ratio was varied from 1 to 2 , binder/plasticizer ratio was increased from 0.5 to 0.7 and dispersant content was ranged from $1 \mathrm{wt} \%$ to $1.6 \mathrm{wt} \%$, respectively.

PU foams with average pore size around $700 \mu \mathrm{m}$ were cut into a $12 \times 12 \times 18 \mathrm{~mm}$ bar and then immersed into the ceramic slurry under vacuum to drive the HA slurry to fill the pores of the PU foams. The HA-saturated foams were then dried in a freeze dryer (Christ 101541, Germany) for $24 \mathrm{~h}$. The completely dried samples were sintered at $1300^{\circ} \mathrm{C}$ for $4 \mathrm{~h}$ in a furnace (Lenton UAF15/ 10, England) using heating rate of $5^{\circ} \mathrm{C} / \mathrm{min}$.

\subsection{Characterization}

The specific surface area of the HA powder was determined by the BET method, using Autosorb-1C, Quantachrome instrument. Rheological behaviour of HA suspensions was performed on a Rheometer: Gemini 200HR nano (Malvern Instrument, UK) in the shear rate range of $0 \cdot 1-100 \mathrm{~s}^{-1}$. The samples before and after sintering were measured and calculated to find the volume shrinkage. Universal testing machine (Instron 55R4502) was employed to measure the compressive strength of sintered samples at a crosshead speed of $0.5 \mathrm{~mm} / \mathrm{min}$. The specimen morphology was observed under a scanning electron microscope (SEM, JEOL 6301F).

\section{Results and discussion}

Figure 1 shows the XRD patterns of HA powder synthesized by a solid-state reaction. The HA powder can be indexed as the crystallization of hydroxyapatite referring to the JCPDS no. 09-0432. As-synthesized powder has a specific surface area of $46.98 \mathrm{~m}^{2} / \mathrm{g}$. After calcination at $900^{\circ} \mathrm{C}$ for $1 \mathrm{~h}$, the powder showed a sharper peak compared to the as-synthesized powder, which indicates a larger crystal size and higher crystallinity. However, only one peak due to the decomposition of $\beta$-TCP appeared as a minor peak. HA powder also became light blue and the loss on ignition was approximately $11 \%$. The HA colour changed to light blue due to the impurity from trace elements (Gittings et al 2009). In addition, the specific surface area of calcinated powder was reduced to $14.88 \mathrm{~m}^{2} / \mathrm{g}$ due to the calcination. Therefore, the homogeneity and the electrostatic stabilization of HA powder were observed (Sadeghian et al 2006).

\subsection{Effect of HA/water ratio}

Porous HA used in medical applications should have an appropriate mechanical strength, hence, the HA/water ratio should be as high as possible which offer no restriction to the flow ability. In order to optimize the HA/water ratio and the flow ability, the dependence of HA/water ratio on flow behaviour of HA slurry was investigated. The suspensions of HA powder were prepared with HA/ water ratio ranging from 1 to 2 . The rheological curves of the slurries were demonstrated in figure 2. All the slurries presented a shear thinning behaviour as the viscosity decreased with the shear rate increase. The result also showed that viscosity would increase by the increase of $\mathrm{HA} /$ water ratio which is in agreement with the report by Chen et al (2006). This suggests that viscosity is considerably influenced by the HA/water ratio. In addition, it

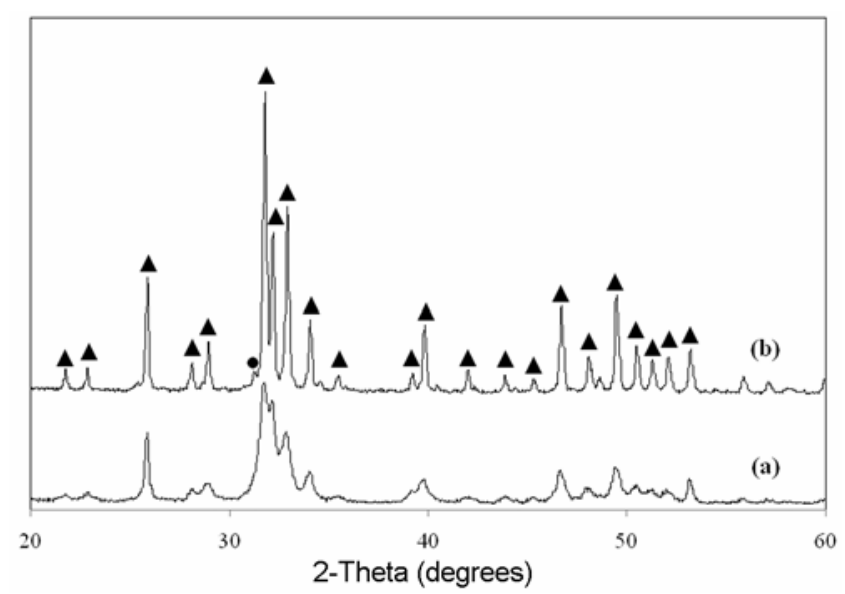

Figure 1. XRD patterns of HA: (a) as-synthesized and (b) HA calcined at $900^{\circ} \mathrm{C}$ for $1 \mathrm{~h}(\boldsymbol{\Lambda}, \mathrm{HA}$ and $\boldsymbol{\bullet}, \beta$-TCP $)$. 
was difficult to attain slurry with good rheological properties if the HA/water ratio was above 2 which is evident from the relatively high viscosity and non smooth curve. Therefore, the slurries with the HA/water ratio above 2 did not meet the conditions required for the polymeric sponge method.

Table 1 presents the physical and mechanical properties of HA porous scaffolds with varying HA/water ratios. The results revealed a decrease in volume shrinkage with an increase in HA/water ratio, except the sample with $\mathrm{HA} /$ water ratio equal to 1 . Apparently, the slurry had high water content with induced weak packing of the particles. Therefore, a poor sinterability of HA ceramic structured by the colloidal processing was observed.

HA/water ratio did not only influence the volume shrinkage but also the compressive strength of sintered samples. The compressive strength of porous ceramic generally increases with the rising solid loading of the slurry (Nor et al 2008). However, the sample prepared from the slurry with HA/water ratio of 1.6 showed the strongest porous hydroxyapatite ceramics, exhibiting an optimum between low viscosity and high solid content. Thus, this slurry was chosen to adjust in further experiments.

Table 1. The influence of HA/water ratio on volume shrinkage and compressive strength of HA scaffolds.

\begin{tabular}{lcc}
\hline HA/water & $\begin{array}{c}\text { Volume } \\
\text { shrinkage (\%) }\end{array}$ & $\begin{array}{c}\text { Compressive } \\
\text { strength (MPa) }\end{array}$ \\
\hline 1.0 & 34.87 & $0 \cdot 28 \pm 0 \cdot 17$ \\
1.3 & 50.77 & $1 \cdot 12 \pm 0.26$ \\
1.6 & 42.89 & $1.99 \pm 0.54$ \\
2.0 & 39.09 & $1.74 \pm 0.87$ \\
\hline
\end{tabular}

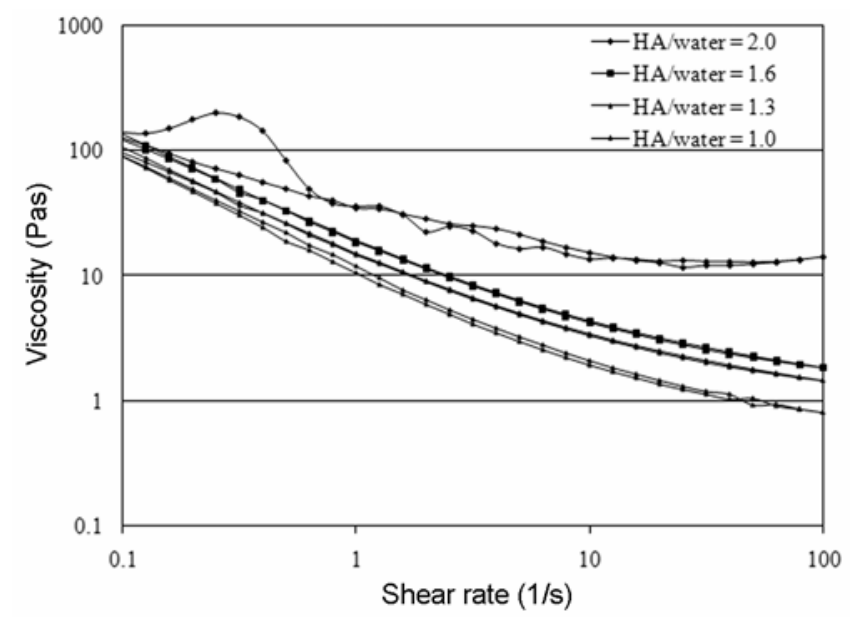

Figure 2. Flow behaviour and viscosity of hydroxyapatite slurry as a function of $\mathrm{HA} /$ water ratio.

\subsection{Effect of binder/plasticizer ratio}

The effect of binder/plasticizer ratio is determined using the HA concentrated suspensions with different binder/ plasticizer ratios varying from 0.6 to 1.0 and a constant $\mathrm{HA} /$ water ratio of 1.6 . The viscosity of the slurry increased with increasing binder/plasticizer ratio as presented in figure 3 . The role of the plasticizer is to reduce the glass transition temperature and the viscosity of the suspension, therefore, the higher the amount of plasticizer, the lower the viscosity. On the other hand, an increase in the amount of plasticizer could result in an easier handling of green ceramic, but lacking in strength, particularly when the low molecular weight of plasticizer was added (Tian et al 2007).

Table 2 demonstrates the influence of binder/plasticizer ratio on the shrinkage and the compressive strength of HA porous ceramics. The increase in binder/plasticizer ratio raised the shrinkage of HA during sintering. However no change in compressive strength could be observed over the range of the binder/plasticizer ratio. Though, the slurry with binder/plasticizer ratio at 0.7 obtained an optimum shrinkage and compressive strength.

\subsection{Effect of dispersant content}

HA is normally a positive charge which is associated with the specific adsorption of $\mathrm{Ca}^{2+}$ ions or to the favourable

Table 2. The effect of binder/plasticizer on volume shrinkage and compressive strength of HA scaffolds.

\begin{tabular}{lcc}
\hline Binder/plasticizer & $\begin{array}{c}\text { Volume } \\
\text { shrinkage (\%) }\end{array}$ & $\begin{array}{c}\text { Compressive } \\
\text { strength (MPa) }\end{array}$ \\
\hline 0.5 & $46 \cdot 72$ & $1 \cdot 06 \pm 0.50$ \\
$0 \cdot 7$ & 49.16 & $2 \cdot 00 \pm 1 \cdot 36$ \\
$1 \cdot 0$ & 51.40 & $0 \cdot 41 \pm 0 \cdot 14$ \\
\hline
\end{tabular}

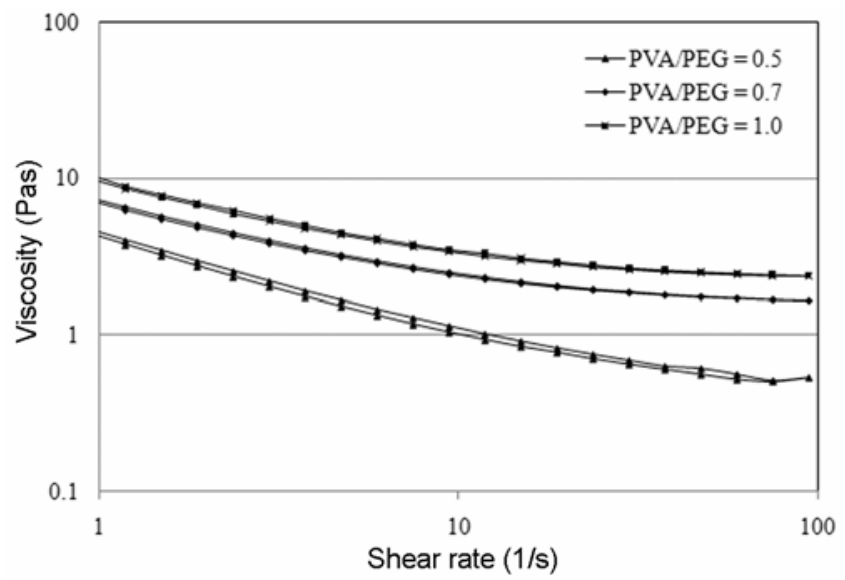

Figure 3. Flow behaviour and viscosity of hydroxyapatite slurry as a function of binder/plasticizer ratio. 
dissolution of phosphate ions from the apatite surface (Sadeghian et al 2006). Therefore, the addition of dispersants with high negative charge would prevent the agglomeration of the suspension as a result of electrostatic stabilization (Rodriguez-Lorenzo et al 2001; Zhang et al 2006). Thus, the effect of dispersant content on the

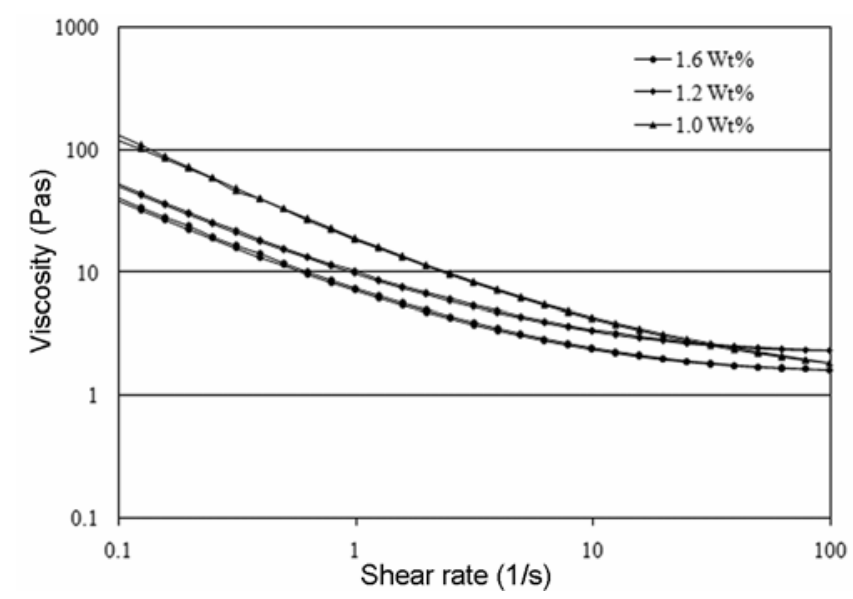

Figure 4. Flow behaviour and viscosity of hydroxyapatite slurry as a function of dispersant content.

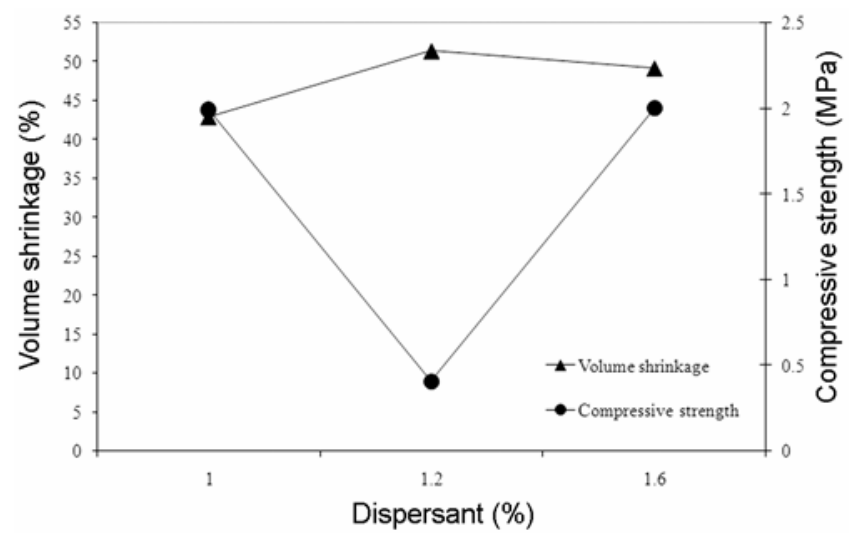

Figure 5. The influence of dispersant content on the firing shrinkage and compressive strength of HA ceramics.

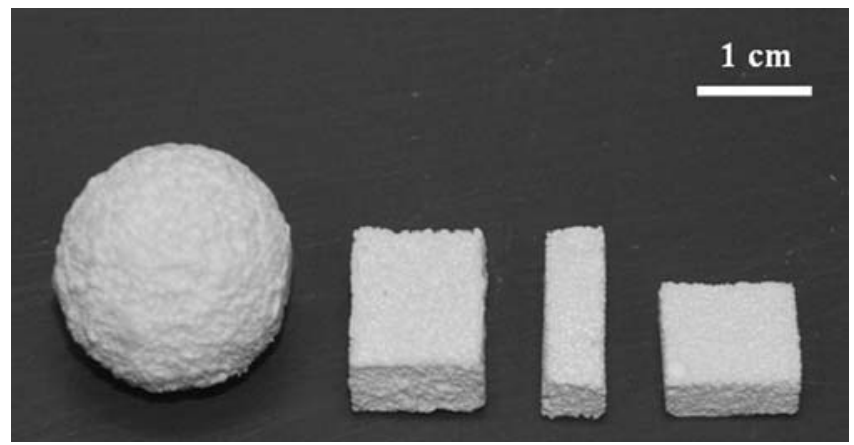

Figure 6. Porous hydroxyapatite bodies of various shapes produced via polymeric sponge method using HA slurry. rheological properties of the suspensions with its values varying from $1.0 \mathrm{wt} \%$ to $1.6 \mathrm{wt} \%$ is investigated. Figure 4 presents the flow behaviour of slurry which depends on the amount of dispersant agent. All the slurries showed a decrease of shear thinning flow behaviour as the shear rate increased. The viscosity of slurry was also declined with the increasing amount of dispersant. The lowest viscosity was observed at the highest dispersant amount of $1.6 \mathrm{wt} \%$. This implies that the adsorbed dispersant on the surface of the HA powder is enough to prevent HA particle-particle attraction. Since the dispersant probably coated on the surface of HA powders, the HA powders could act as a mono-dispersed powder because of the electrostatic stabilization and consequently, reduce the slurry viscosity.
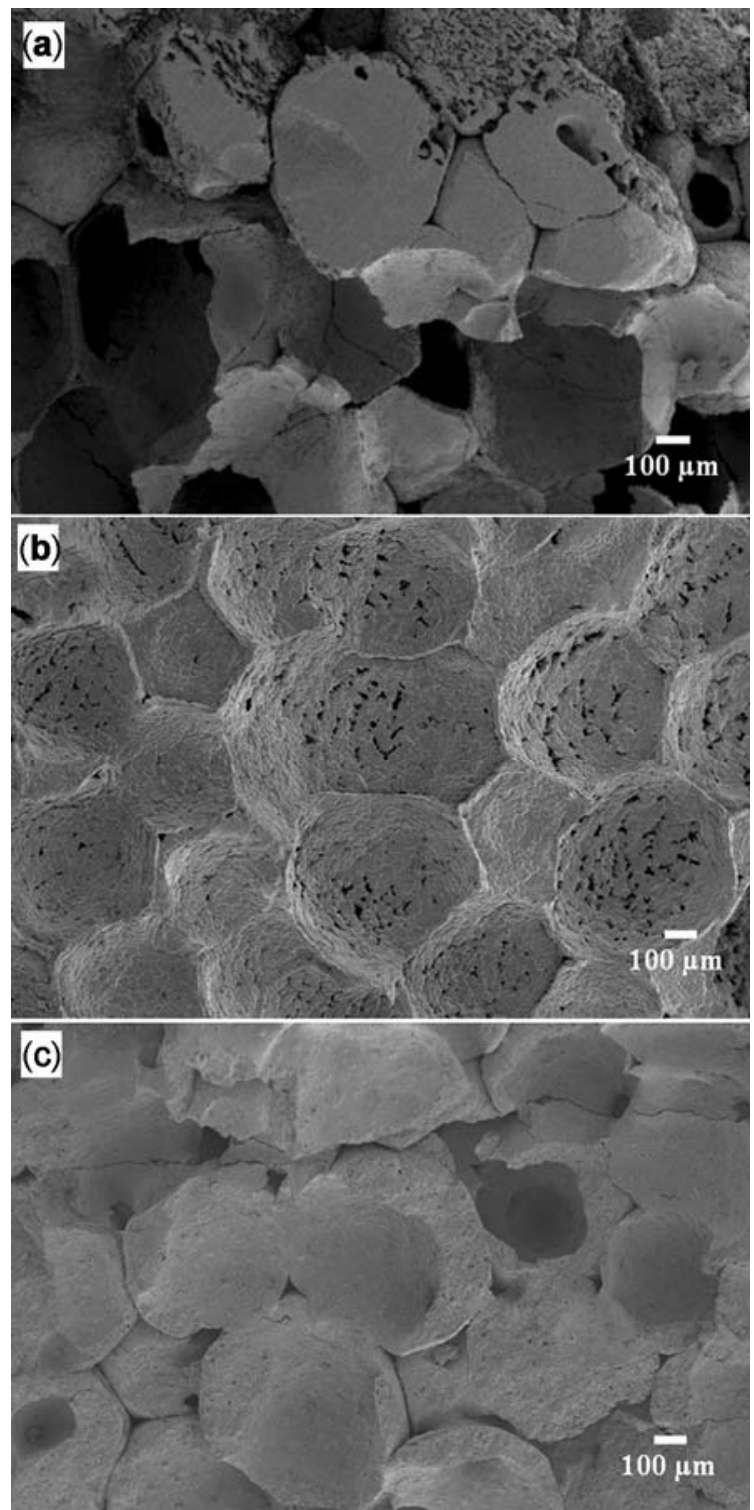

Figure 7. SEM images of sintered sample: (a) Pure HA, (b) HA-loaded $\mathrm{SiO}_{2}$ and (c) HA-loaded $\mathrm{SiC}$. 
Table 3. Physical and mechanical properties of porous samples.

\begin{tabular}{lcc}
\hline Samples & $\begin{array}{c}\text { Volume } \\
\text { shrinkage (\%) }\end{array}$ & $\begin{array}{c}\text { Compressive } \\
\text { strength (MPa) }\end{array}$ \\
\hline Pure HA & $65 \cdot 75$ & $16 \cdot 32 \pm 3.00$ \\
HA-loaded $\mathrm{SiO}_{2}(2 \mathrm{wt} \%)$ & 46.66 & $16 \cdot 65 \pm 1.93$ \\
HA-loaded $\mathrm{SiC}(2 \mathrm{wt} \%)$ & 48.86 & $6 \cdot 34 \pm 1.40$ \\
\hline
\end{tabular}

In figure 5, no significant trend on the firing shrinkage and compressive strength of HA ceramic is observed as the dispersant content increased. The results demonstrated that the increase in mechanical strength occurred when $54 \mathrm{wt} \% \mathrm{HA}(\mathrm{HA} /$ water ratio $=1 \cdot 6)$ was used in combination with $1.6 \mathrm{wt} \%$ dispersant.

\subsection{The preparation of hydroxyapatite scaffolds}

To improve the mechanical strength of porous scaffolds, $\mathrm{SiC}$ and $\mathrm{SiO}_{2}$ powders were added in the optimized stable slurry. The various shapes of HA porous ceramics can be produced by polymeric sponge process and they are shown in figure 6 . The physical and mechanical properties of the hydroxyapatite scaffolds fabricated under vacuum condition were reported in table 3 . It was found that the compressive strength of pure-HA scaffolds reached $16 \mathrm{MPa}$. The addition of $\mathrm{SiC}$ lowers both shrinkage and compressive strength of porous samples. In comparison, when $\mathrm{SiO}_{2}$ was added, it is observed that only volume shrinkage decreased while the compressive strength is kept at $16 \mathrm{MPa}$. Therefore, a few percentage of $\mathrm{SiO}_{2}$ in HA slurry could improve the sinterability of hydroxyapatite ceramics as a result of a smaller shrinkage.

The SEM images of hydroxyapatite scaffolds in figure 7 illustrated the microstructure of macroporous HA ceramics with an average pore size of about $500 \mu \mathrm{m}$. Significantly, better sinterability among HA particles had been observed in HA-loaded $\mathrm{SiO}_{2}$ samples which well corresponds with the firing shrinkage data. Therefore, $\mathrm{SiO}_{2}$ could play an important role as a sintering aid which encourages a better firing shrinkage of porous ceramics.

\section{Conclusions}

In this study, all the HA slurries showed a shear thinning behaviour and they are highly dependent on HA/water, binder/plasticizer ratios and dispersant content. The optimized stable slurry suitably used for polymeric sponge technique should contain 54 wt\% HA (HA/water ratio of 1.6), binder/plasticizer ratio of 0.7 in combination with $1.6 \mathrm{wt} \%$ dispersant. The macroporous hydroxyapatite with the average pore size of about $500 \mu \mathrm{m}$ can be produced and its compressive strength of $16 \mathrm{MPa}$ is achieved when coupled with the addition of $\mathrm{SiO}_{2}$ for reducing the volume shrinkage and good sinterability.

\section{Acknowledgements}

This work was performed under the support of National Metal and Materials Technology Center, the Ministry of Science and Technology of Thailand, under project no. MT-B-49-BMD-07-131-I.

\section{References}

Chen B, Zhang Z, Zhang J, Dong M and Jiang D 2006 Mat. Sci. Eng. A435 198

Gardini D and Galassi C 2003 J. Am. Ceram. Soc. 88271

Gittings J P, Bowen C R, Dent A C E, Turner I G, Baxter F R and Chaudhuri J B 2009 Acta Biomater. 5743

Itoh S, Nakamura S, Nakamura M, Shinomiya K and Yanashita K 2006 Biomaterials 275572

Kweh S W K, Khor K A and Cheang P 1999 J. Mat. Pro. Tech. 89-90 373

Liu D M 1998 Ceram. Int. 24441

Nor M M, Hong C C, Ahmad Z A and Akil H M 2008 J. Mater. Process. Technol. 207235

Ozgur N and Tas A C 1999 J. Eur. Ceram. Soc.19 2569

Pretto M, Costa A L, Landi E, Tampieri A and Galassi C 2003 J. Am. Ceram. Soc. 861534

Ramay H R and Zhang M 2003 Biomaterials 243293

Rodriguez-Lorenzo L M, Vallet-Regi $\mathrm{M}$ and Ferreira J M F 2001 Biomaterials 221847

Sadeghian Z, Heinrich J G and Moztarzadeh F 2006 Ceram. Int. 32331

Saiz E, Gremillard L, Menendez G, Miranda P, Gryn K and Tomsia A P 2007 Mat. Sci. Eng. C27 546

Sopyan I, Mel M and Ramesh S 2007 Sci. Tech. Adv. Mat. 8 116

Tian J and Tian J 2001 J. Mater. Sci. 363061

Tian T, Jiang D, Zhang J and Lin Q 2007 J. Eur. Ceram. Soc. 272671

Zhang H G and Zhu Q 2007 J. Mater Sci: Mater. Med. 181825

Zhang J, Maeda M, Kotobuki N, Hirose M, Ohgushi H, Jiang D and Iwasa M 2006 Mater. Chem. Phys. 99398 